\title{
Respiratory Therapist Job Perceptions: The Impact of Protocol Use
}

\author{
Ashley Y Metcalf PhD, James K Stoller MD MSc FAARC, Marco Habermann PhD, and \\ Timothy D Fry PhD
}

\begin{abstract}
BACKGROUND: Demand for respiratory care services and staffing levels of respiratory therapists (RTs) is expected to increase over the next several years. Hence, RT job satisfaction will be a critical factor in determining recruitment and retention of RTs. Determinants of RT job satisfaction measures have received little attention in the literature. This study examines the use of respiratory care protocols and associated levels of RT job satisfaction, turnover intentions, and job stress. METHODS: Four-hundred eighty-one RTs at $\mathbf{4 4}$ hospitals responded to an online survey regarding job satisfaction, turnover intentions, and job stress. Random coefficient modeling was used for analysis and to account for the nested structure of the data. RESULTS: Higher levels of RT protocol use were associated with higher levels of job satisfaction, lower rates of turnover intentions, and lower levels of job stress. In addition, RTs with greater experience had higher levels of job satisfaction, and RTs working at teaching hospitals had lower rates of turnover intentions. CONCLUSIONS: The study extends prior research by examining how the use of respiratory care protocols favorably affects RTs' perceptions of job satisfaction, turnover intention, and job stress. In a time of increasing demand for respiratory care services, protocols may enhance retention of RTs. Key words: respiratory care; protocols; job satisfaction; turnover; empirical research; organizational study. [Respir Care 2015;60(11):1556-1559. (C) 2015 Daedalus Enterprises]
\end{abstract}

\section{Introduction}

Current forces affecting health-care management require an increasing supply of capable allied health providers. The increasing life expectancy and the aging population in the United States indicate the need for more health-care providers to care for individuals with a greater burden of illness. At the same time, physician shortages are projected; the Association of American Medical Colleges has

Drs Metcalf and Habermann are affiliated with the College of Business, Ohio University, Athens, Ohio. Dr Stoller is affiliated with the Education Institute and the Department of Pulmonary and Critical Care Medicine, Respiratory Institute, Cleveland Clinic, Cleveland, Ohio. Dr Fry is affiliated with the Moore School of Business, University of South Carolina, Columbia, South Carolina.

The authors have disclosed no conflicts of interest.

Correspondence: Ashley Y Metcalf $\mathrm{PhD}$, College of Business, Ohio University, 306 Copeland Hall, Athens, OH 45701. E-mail: metcalfa@ ohio.edu.

DOI: $10.4187 /$ respcare.04156 forecasted a shortage of 130,600 physicians by 2025,1 equally comprised of specialists and primary care physicians. Finally, in the interest of standardizing and optimizing care in a cost-attentive environment, health-care organizations are increasingly designing care paths for common illnesses that call for allied health providers and nurses to practice at the top of their license. The use of respiratory care protocols is one example of utilizing respiratory therapist (RT) assessment skills in an effort to maximize their job duties within their licensure.

In the context of forces affecting health care, the Bureau of Labor Statistics has predicted that the demand for RTs will increase by $19 \%$ from 2012 to 2022 , leading to an estimated 22,700 vacant positions nationwide. ${ }^{2}$ This growing demand creates the need to both train new RTs and retain existing practitioners (eg, by minimizing turnover and the number of RTs leaving the health-care field). Although RT turnover has received relatively little attention, Stoller et $\mathrm{al}^{3}$ reported annual turnover rates of $3-18 \%$ in the Cleveland Clinic Health System of 9 hospitals and showed that RT turnover incurred substantial expense to the hospital system. 


\section{RT Job Perceptions and Impact of Protocols}

Because employees' perceptions and experiences in their jobs have been shown to affect productivity and performance, ${ }^{4}$ respiratory care managers must consider how work design impacts RT job satisfaction and turnover intentions. A previously reported multi-hospital, survey-based report regarding determinants of respiratory care protocol use ${ }^{5}$ provides the basis for this more detailed analysis of the impact of respiratory care protocol use on RT job satisfaction and turnover intentions. Specifically, we examine the effect of respiratory care protocol use on RT overall job satisfaction, turnover intentions, and perceived job stress.

\section{Methods}

\section{Sample}

Acute care, non-government hospitals in the United States were included in this study. Within such hospitals, the unit of analysis was the individual hospital unit, of which 4 types were analyzed: the ICU, emergency department, adult in-patient unit, and neonatal ICU. The recruitment of hospitals and participating RTs and managers and the deployment of the online surveys were as described previously. ${ }^{5}$ In brief, collected data elements included RTs' perceptions of job satisfaction, turnover intentions, and job stress. Managers were queried regarding the level of protocol use within each participating hospital unit. In total, 44 hospitals with 99 units and 481 RTs were included in the analysis. The survey methodology was approved as exempt from written consent by the institutional review board of the University of South Carolina; participants granted verbal informed consent.

\section{Data Analysis}

Overall use of respiratory care protocols was measured as the percentage of subjects $(0-100 \%)$ within each unit who were treated according to an RT-directed respiratory care protocol. Job satisfaction, turnover intentions, and job stress were measured using Likert scale-type responses $(1=$ strongly disagree, $5=$ strongly agree $)$. Additional control variables were included to account for RT experience (y) and education (bachelor's degree or higher vs associate's degree). Differing levels of experience and education may be additional reasons for variations in job satisfaction, turnover intentions, and stress. Unit controls (ICU, neonatal ICU, and emergency department) were included as binary control variables in the analysis and are interpreted in the results compared with adult in-patient units. Hospital controls for size (measured as number of beds) and teaching status (teaching vs non-teaching) were also included in the analysis. It is plausible that unit type,

\section{QUICK LOOK}

\section{Current knowledge}

The Bureau of Labor Statistics has predicted that the demand for respiratory therapists (RTs) will grow by 19\% from 2012 to 2022, leading to an estimated 22,700 vacant positions nationwide. This growing demand creates the need to train new RTs and to retain existing practitioners. Annual turnover rates of 3-18\% have been reported in the Cleveland Clinic Health System, demonstrating that RT turnover adds substantial expense to the hospital system.

\section{What this paper contributes to our knowledge}

In a survey of 44 hospitals and nearly 500 RTs, the use of respiratory care protocols was associated with higher RT job satisfaction, lower rates of turnover intentions, and lower levels of job stress. RTs with more experience had higher levels of job satisfaction but higher levels of job stress. RTs working at teaching hospitals tended to have lower turnover. These findings are important for recruitment and retention of the workforce.

hospital size, and teaching status may account for the differences in resources that could impact overall RT satisfaction and turnover intentions. Hospital controls for size and teaching status were retrieved from the American Hospital Association database (http://www.ahadataviewer. com, Accessed March 15, 2013). Details of the survey items are shown in Figure 1.

Because RTs are nested within hospital units, traditional regression methods would provide biased results. ${ }^{6}$ Thus, random coefficient modeling was used for analysis to account for the nested structure of the data. Stata 13 software (StataCorp, College Station, Texas) was used for analysis.

\section{Results}

Table 1 shows the results of the random coefficient models. Higher levels of protocol use $(P<.01)$ and higher levels of experience $(P<.05)$ were associated with higher RT job satisfaction. Furthermore, higher levels of protocol use $(P<.05)$ and working at a teaching hospital $(P<.10)$ were associated with lower rates of RT turnover intentions. High levels of protocol use were associated with lower levels of job stress $(P<.05)$. However, working in the ICU $(P<.05)$ or emergency department $(P<.05)$ and greater experience $(P<.01)$ increased job stress. RT education level and hospital size did not appear to impact job satisfaction, turnover intentions, or job stress. 


\author{
Survey Questions \\ [survey respondent in brackets] \\ Hospital Unit: (1) ER, (2) ICU, (3) NICU, (4) Adult Inpatient \\ Use of RT driven Protocols [manager] \\ Responses 0-100\% \\ (1) What percentage (\%) of patients in this unit are typically \\ assigned orders of RT "Assess and Treat" (via RT protocol?) \\ Job Satisfaction [therapist] \\ Responses: 1 - strongly disagree to 5 - strongly agree \\ (1) I am quite satisfied with my job in general. \\ Turnover Intention [therapist] \\ Responses: 1 - strongly disagree to 5 - strongly agree \\ (1) I frequently think of quitting my job. \\ (2) I am planning to search for a new job in the next 12 months. \\ Job Stress [therapist] \\ Responses: 1 - strongly disagree to 5 - strongly agree \\ (1) I experience tension from my job. \\ (2) Aspects of my job are a source of frustration for me. \\ Education [therapist] \\ Describe your level of education \\ (1) Associates Degree \\ (2) Bachelors Degree or higher \\ Experience [therapist] \\ Responses in number of years. \\ (1) How many years have you been a respiratory therapist?
}

Fig. 1. Survey questions. $\mathrm{ER}=$ emergency room; $\mathrm{NICU}=$ neonatal ICU; RT = respiratory therapist.

\section{Discussion}

There are 4 main findings of this study on respiratory care protocol use and RTs' perceptions. (1) Greater use of respiratory care protocols was associated with higher RT job satisfaction, lower rates of turnover intentions, and lower levels of job stress. (2) RTs with more experience had greater levels of job satisfaction and, interestingly, higher levels of job stress. (3) RTs working in the ICU and emergency department tended to have higher levels of job stress compared with those working in an adult in-patient unit. (4) RTs working at teaching hospitals tended to have lower rates of turnover intentions.

In the context of a growing need for RTs, little attention has been given to determinants of RT turnover or job satisfaction. The 2014 AARC Respiratory Therapist Human Resource Study found that $64 \%$ of hospitals had turnover rates similar to the previous year, with $18 \%$ reporting increases in turnover and $18 \%$ reporting decreases. ${ }^{7}$ A previous study ${ }^{3}$ examined the rate and correlates of RT turnover within the Cleveland Clinic Health System. Annual turnover rates varied by hospital from 3 to $18 \%$, and the parameter that bore the highest association with observed turnover rates was the ratio of hospital beds to RTs, with higher ratios associated with higher turnover $\left(r^{2}=0.61\right)$. Although respiratory care protocols were widely used in Cleveland Clinic hospitals, neither the association between protocol use rates at specific hospitals and RT turnover rates nor an individual RT's job satisfaction was examined in the earlier study.

This study extends available research regarding determinants of RT job satisfaction by analyzing it in several ways. This is, to our knowledge, the first study to examine correlates of an individual RT's perception of job satisfaction with turnover intention and job stress. The findings suggest that a formal protocol program may be a tool for retaining RTs and may be especially important in an environment where there is competition for a constrained supply of RTs.

This study has several limitations. First, although recognizing that the hospital bed/RT ratio correlates with RT turnover rates from prior work, ${ }^{3}$ data regarding hospital bed/RT ratios were not available from participating insti-

Table 1. Results of Random Coefficient Models

\begin{tabular}{|c|c|c|c|}
\hline \multirow{2}{*}{ Independent Variables } & \multicolumn{3}{|c|}{ Dependent Variables } \\
\hline & Job Satisfaction & Turnover Intentions & Job Stress \\
\hline Protocol use, mean $\pm \mathrm{SE}$ & $0.004 \pm 0.001^{*}$ & $-0.003 \pm 0.002 \dagger$ & $-0.003 \pm 0.002 \dagger$ \\
\hline Experience, mean $\pm \mathrm{SE}$ & $0.007 \pm 0.003 \dagger$ & $-0.0002 \pm 0.004$ & $0.018 \pm 0.005^{*}$ \\
\hline Education, mean $\pm \mathrm{SE}$ & $-0.089 \pm 0.071$ & $0.127 \pm 0.098$ & $0.137 \pm 0.100$ \\
\hline $\mathrm{ICU}$, mean $\pm \mathrm{SE}$ & $-0.154 \pm 0.093$ & $0.150 \pm 0.127$ & $0.319 \pm 0.137 \dagger$ \\
\hline Neonatal ICU, mean $\pm \mathrm{SE}$ & $-0.131 \pm 0.147$ & $0.340 \pm 0.204$ & $0.257 \pm 0.209$ \\
\hline Emergency department, mean $\pm \mathrm{SE}$ & $0.089 \pm 0.142$ & $0.256 \pm 0.196$ & $0.447 \pm 0.198 \dagger$ \\
\hline Teaching hospital, mean $\pm \mathrm{SE}$ & $-0.064 \pm 0.093$ & $-0.229 \pm 0.129 \ddagger$ & $-0.109 \pm 0.141$ \\
\hline Hospital size, mean $\pm \mathrm{SE}$ & $0.0001 \pm 0.0001$ & $0.0002 \pm 0.0001$ & $0.0003 \pm 0.0002$ \\
\hline$n$ & 479 & 479 & 481 \\
\hline $\begin{array}{l}* P<.01 . \\
\dagger P<.05 . \\
\ddagger P<.10 .\end{array}$ & & & \\
\hline
\end{tabular}


tutions in this survey. Second, our findings regard RTs' stated turnover intentions, but the cross-sectional design precluded longitudinal assessment to assess actual turnover rates. Still, findings by Griffeth et $\mathrm{al}^{8}$ that turnover intentions correlate with actual turnover support the robustness of our findings. Also, assignments regarding protocol use were based on RT managers' reports rather than actual observation of protocol use (eg, by direct observation, query of hospital information systems). Finally, the survey instrument did not ask respondents about race, sex, or sexual orientation, so these variables were not included in the study.

\section{Conclusions}

Notwithstanding these limitations, in the context of the sparse available literature on determinants of RT turnover, our findings likely have implications for RT practice. Specifically, by showing that respiratory care protocol use is associated with benefits regarding RT turnover and job satisfaction, these results extend our understanding of the benefits of respiratory care protocols..$^{9}$ In addition to their positive effect on allocation of respiratory care treatments, improved outcomes, and reduced costs, ${ }^{10-12}$ this study suggests that respiratory care protocols can also be used to increase RT job satisfaction and reduce turnover intentions. In an environment of increasing demand and job shortages, RT job satisfaction and turnover intentions will be increasingly important to managers.

\section{REFERENCES}

1. Association of American Medical Colleges. Myths and facts: the physician shortage. https://www.aamc.org/download/386378/data/ 07252014.pdf. Accessed February 19, 2015.
2. Bureau of Labor Statistics, United States Department of Labor. Occupational outlook handbook, respiratory therapists, 2014-2015 edition. http://www.bls.gov/ooh/healthcare/respiratory-therapists.htm. Accessed February 19, 2015.

3. Stoller JK, Orens DK, Kester L. The impact of turnover among respiratory care practitioners in a health care system: frequency and associated costs. Respir Care 2001;46(3):238-242.

4. Judge TA, Thoresen CJ, Bono JE, Patton GK. The job satisfactionjob performance relationship: a qualitative and quantitative review. Psychol Bull 2001;127(3):376-407.

5. Metcalf AY, Stoller JK, Fry TD, Habermann M. Patterns and factors associated with respiratory care protocol use. Respir Care 2015; 60(5):636-643.

6. Snijders TA, Bosker RJ. Multilevel analysis: an introduction to basic and advanced multilevel modeling. Thousand Oaks, CA: Sage Publications; 2004:38-85.

7. Shaw RC, Benavente JL. AARC RT human resource survey of acute care hospital employers. Irving, TX: American Association for Respiratory Care; 2014.

8. Griffeth RW, Hom PW, Gaertner, S. A meta-analysis of antecedents and correlates of employee turnover: update, moderator tests, and research implications for the next millennium. J Manage 2000;26(3): 463-488.

9. Stoller JK. The effectiveness of respiratory care protocols. Respir Care 2004;49(7):761-765.

10. Harbrecht BG, Delgado E, Tuttle RP, Cohen-Melamed MH, Saul MI, Valenta CA. Improved outcomes with routine respiratory therapist evaluation of non-intensive-care-unit surgery patients. Respir Care 2009;54(7):861-867.

11. Kollef MH, Shapiro SD, Silver P, St John RE, Prentice D, Sauer S, et al. A randomized, controlled trial of protocol-directed versus physician-directed weaning from mechanical ventilation. Crit Care Med 1997;25(4):567-574.

12. Stoller JK, Mascha EJ, Kester L, Haney D. Randomized controlled trial of physician-directed versus respiratory therapy consult servicedirected respiratory care to adult non-ICU inpatients. Am J Respir Crit Care Med 1998;158(4):1068-1075.

This article is approved for Continuing Respiratory Care Education credit. For information and to obtain your CRCE

(free to AARC members) visit

www.rcjournal.com

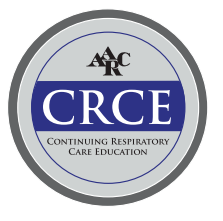

